\title{
Rural nurses' continuing education needs: A U.S. multi-site survey reveals challenges and opportunities
}

\author{
Roseanne M. Fairchild ${ }^{1}$, Marcee Everly ${ }^{1}$, Linda Walters ${ }^{1}$, Renee Bauer ${ }^{1}$, Stephanie Laws ${ }^{2}$, Louise \\ Anderson $^{3}$
}

1. College of Nursing, Health, and Human Services, Indiana State University, Terre Haute, Indiana, USA. 2. Rural Health Innovation Collaborative Richard Lugar Center for Rural Health, Terre Haute, Indiana, USA. 3. Area Health Education Center (AHEC), Indiana State University, Terre Haute, Indiana, USA

Correspondence: Roseanne Fairchild. Address: Indiana State University, 1433 N. 6 1⁄2 Street, Landsbaum Center for Health Education, College of Nursing, Health, and Human Services, Terre Haute, Indiana 47807, USA. Email: roseanne.fairchild@indstate.edu.

Received: September 27, 2012 Accepted: November 21, 2012 Online Published: December 11, 2012

DOI : $10.5430 /$ jnep.v3n5p45

URL: http://dx.doi.org/10.5430/jnep.v3n5p45

\section{Abstract}

Background: Provision of relevant, evidence-based continuing education (CE) is an integral part of maintaining a highly competent rural nursing workforce. Numerous tangible and intangible barriers exist to nurses' participation in CE in rural settings. Major barriers to accessibility and participation in CE for rural nurses include: 1) Geographic isolation, 2) lack of perceived administrative, financial, and/or technological resources and support, 3) lack of time due to workload, inadequate staffing, and/or travel distance, 4) lack of relevance of continuing education topics, and 5) lack of a dedicated on-site nurse educator. Proactive development of academic-practice partnerships is important to support rural care providers regarding CE delivery. The purpose of this study was to assess perceptions of CE needs of nursing unit staff working in a group of health care facilities in a rural region of midwestern U.S.

Methods: A cross-sectional CE needs assessment survey was conducted in winter of 2010 with rural health care providers $(\mathrm{N}=302 / 1107$; response rate 27\%) working in rural healthcare facilities $(\mathrm{N}=40)$, including rural hospitals $(\mathrm{n}=10)$ and long-term care (LTC) facilities ( $\mathrm{n}=30$ ). A well-validated 72-item Likert-type survey was distributed via a secure online university survey platform, and included assessment of $59 \mathrm{CE}$ need areas. Internal consistency reliability was 0.87 . Data were analyzed using SPSS software, version 16.0.

Results: Descriptive statistics revealed a greater number of licensed practical nurses and nursing assistants working in rural LTC's ( $27.2 \%$ and $62.5 \%$, respectively) compared to rural hospital setting ( $14 \%$ and $15 \%$, respectively). There are a large number of associate degree-prepared nurses (63\%) working in the participating rural hospitals compared to LTC setting (8.4\%). Respondents' priority learning needs included: 1) Review aspects of medication administration/drug interactions; 2) improve skills in patient assessment (physical/mental); 3) increase knowledge of management of patients with comorbidities; 4) promotion of patient safety; 5) enhance communication skills/teamwork; 6) increase lifelong learning. Student's $t$ tests revealed LTC nursing unit staff reported significantly higher priority learning needs in "manage aggressive behavior (verbal/physical)" ( $t=2.044, \mathrm{~d} f=300, \alpha=.003)$, "family participation in care" $(t=2.470, \mathrm{~d} f=300, \alpha=$ 
.036), and "maintain standards of care" ( $t=2.880, \mathrm{~d} f=300, \alpha=.042)$, whilst acute care nursing staff reported a significantly higher priority learning need in "manage a crisis" $(t=2.122, \mathrm{~d} f=300, \alpha=.050)$.

Conclusions: Study results revealed key learning needs related to several aspects of patient care delivery for rural nursing unit staff who are primarily nursing assistants or nurses meeting minimum state educational requirements. Basic healthcare workforce training does not typically emphasize continuous quality improvements, or how to recognize and develop an evidence-based practice at the entry level. The potential for nursing knowledge stagnation among entry level nursing unit staff in rural settings needs to be addressed to help break down isolation barriers impacting knowledge, attitudes and behaviors of health care providers practicing in rural health care facilities.

\section{Key words}

Rural continuing nurses’ education, Academic-practice partnership, Evidenced-based practice

\section{Introduction}

The provision of relevant, evidence-based continuing education (CE) is an integral part of maintaining a highly competent rural nursing workforce. However, there are numerous tangible and intangible barriers to nurses' participation in $\mathrm{CE}$ in rural settings ${ }^{[1]}$. The major barriers to accessibility and participation in CE for nurses working in rural settings have been well-documented:

Geographic isolation ${ }^{[1-4]}$ :

- Lack of perceived administrative, financial, and/or technological resources ${ }^{[2-7]}$;

- Lack of time due to workload, inadequate staffing, and/or travel distance ${ }^{[2,4,6]}$;

- Lack of relevance of continuing education topics ${ }^{[2,6]}$;

- Lack of a dedicated on-site nurse educator to lead CE planning and education ${ }^{[1]}$.

With this evidence in mind, the proactive development of academic-practice partnerships is particularly important for rural nurse providers, since they face multiple resource-related barriers regarding consistent delivery of $\mathrm{CE}^{[3,4]}$. A lack of personnel, financial resources, and educational technologies also limits access to relevant $\mathrm{CE}$ content ${ }^{[2,3]}$. Initiation of an academic-practice partnership promotes a collaborative community of practice that is better-prepared to discern and respond to rural nurses' developmental learning needs ${ }^{[3]}$.

\subsection{Purpose of the study}

The purpose of this study was to assess the perceptions of the CE needs of nursing unit staff working in a group $(\mathrm{N}=40)$ of rural health care facilities in a rural region of the midwestern U.S.

\subsection{Background}

\subsubsection{Rural staff nurse's perspective}

To develop CE content relevant to the needs of rural nursing unit staff, a few studies have assessed the topic from the staff nurse's perspective ${ }^{[2,4-6]}$. As discussed earlier, most of these studies highlight rural nurse's perceptions of tangible barriers related to access and participation in $\mathrm{CE}^{[2,4-6]}$. One study in particular, reported specific CE needs of rural nurses across a broad range of topics. These needs-based themes for the rural setting included: Health assessment and triage, care of the elderly, living/working in rural communities, chronic disease management, and specialty nursing care areas such as perinatal, mental health, and emergency care nursing ${ }^{[6]}$. In this study, the authors utilized a mixture of CE delivery methods for courses, with an emphasis placed on self-reliance and self-directed learning ${ }^{[6]}$. 


\subsubsection{Rural nurse administrator's perspective}

From the perspective of rural nurse administrators, there is a dearth of literature assessing rural nurses' learning needs. In one study of nurse administrators in rural Australian hospitals, researchers conducted qualitative interviews with nurse leaders $(n=20)$ concerning the learning needs of nursing unit staff ${ }^{[8]}$. Based on the thematic results, rural nurses' learning needs were reported to be important to maintaining safety and quality of care in rural hospitals, and were similar when compared to nurses' perceptions of CE needs reported in the aforementioned nursing unit staff studies ${ }^{[2,4,6]}$.

From the perspective of nursing leadership, the priority learning needs of rural nursing unit staff for the Australian study included mental health assessment, advanced health assessment, and advanced life support ${ }^{[8]}$. Nurse administrators also reported a perceived need for additional continuing education in advanced clinical skills, in light of the fact that in the rural setting, nurses may not have ready access to the support of a physician or more advanced practitioner when a more complex patient presents to the rural hospital ${ }^{[8]}$.

Unique learning needs for rural staff nurses also emerged from the data, related to the development of management and leadership skills ${ }^{[8]}$. Since only a small number of nurses may work in the hospital on any one shift, rural staff nurses frequently found themselves involved in management- and leadership-related duties on the nursing units. As the authors ${ }^{[8]}$ discovered: "Inexperienced nurses were engaged in all facets of management: planning, organizing, staffing, directing, coordinating, reporting and budgeting. The environment of the rural hospital often demanded that new graduates were faced with the complex task of balancing leadership and management" ${ }^{[8]}$, as well as routine patient care duties. In light of a limited number of studies evaluating nurses' continuing education needs in the rural setting, there is a need for further research to explore and expand nursing knowledge related to CE needs of rural nursing unit staff in acute care and LTC settings.

These findings compliment the authors' recent qualitative study of the perceptions of rural nurse administrators ( $\mathrm{N}=40$ ), regarding priority learning needs of nursing unit staff ${ }^{[9]}$. In this concurrent study, rural nurse administrators reported the need for additional CE in the broad areas of clinical nursing skills, patient safety, cultural issues, and holistic, patientcentered delivery of care ${ }^{[9]}$. However, it is important to also assess the perceptions of nursing unit staff regarding the unique challenges they face while delivering care to patients every day in their rural communities. The purpose of this study was to assess the perceptions of the CE needs of nursing unit staff working in a group $(\mathrm{N}=40)$ of rural health care facilities in a rural region of the midwestern U.S.

\section{Method}

\subsection{Setting and sample}

This cross-sectional CE needs assessment study was conducted in a predominantly rural 11-county region of a U.S. Midwestern state in the winter of 2010. Study team members each volunteered to contact 6-7 nurse administrators working in the healthcare facilities in the designated region $(\mathrm{N}=45)$, to explain the purpose of the study, and to assess their interest regarding participation in the study. Forty rural nurse administrators (89\%) subsequently agreed to participate in the study.

Letters from the university's Center for Nurses' Continuing Education describing the study purpose and the desire to work together to create a regional academy-practice partnership in continuing education were also mailed to the nurse administrators. The administrators acknowledged that the study would involve a voluntary, anonymous online CE needs survey for their nursing unit staff. The study team also made a commitment to share study results when tabulated in the aggregate with participating rural health care facilities, and initial community partnership efforts are described elsewhere ${ }^{[9]}$. Regarding ethical considerations for sampling of the study population, the study was designated exempt as a form of CE program evaluation by university's ethical review board (ERB). 


\subsection{Quantitative instrumentation and analysis}

A 72-item Likert-type cross-sectional survey of the perceptions of the CE needs of rural nursing unit staff and management was conducted by distributing a secure online software link via a secure university server and survey platform to participants via email in the region's hospital and LTC settings. Permission was obtained to post informational signs about the survey on the nursing units of the participating rural facilities. The survey site was maintained by the academic partner's college of nursing website, and was monitored regularly for secure access and appropriate online functioning. Participants were directed to email the first author should any questions arise before, during or after survey administration. Since it was more challenging for staff in LTCs to access a computer, the study team would recommend supplementing with paper and pencil surveys in this particular setting.

The online survey format began with a description of the study and its primary purpose, followed by an informed consent statement to either accept and voluntarily participate in the study, or to decline consent and opt out of the study. Opting out of the study automatically linked the nursing unit staff member to an exit page, thus bypassing survey initiation. For participants agreeing to voluntary participation, the online instructions explained that the survey would take approximately 15 minutes to complete, and contained 2 complementary components. The instructions described the survey components, including the first section assessing 59 continuing education need areas (58-Likert-type scale items and one open-ended question), and second section assessing 13 demographic questions.

The first section of the survey assessed nurses' CE needs across 7 domains: 1) Nursing Process, 2) Clinical Problems: Management of the Patient with [Health Condition], 3) Nursing Interactions, 4) Gerontological Care, 5) Patient Care Issues, Interests, and Problems, 6) Managerial Skills, and 7) Professional Issues. The respondents were asked to rate each of 58 educational need areas across 7 domains as they pertained to continuing education based on a 5-point Likert scale, with 5 being "very high priority for me" and 1 being "very low priority for me." The final item in this section was openended, allowing participants to expand on learning need areas, and/or request follow-up in their facility. The second section of the survey asked questions pertaining to age, educational level, professional role, type of healthcare facility, and years of experience.

The survey utilized was an online adaptation of "The Survey of Nurses' Continuing Education Needs", a well-validated 59 item, Likert-type survey that has been utilized in a previous study of U.S. Veteran's Administration hospitals and LTC nursing units, with internal consistency reliability reported as $0.97^{[10]}$. For this study, internal consistency reliability was assessed at 0.87 , and a demographics section was added to collect descriptive data for the study.

\section{Results}

Data generated by nursing unit staff responses to the questionnaire were analyzed and are reported using SPSS software, version 16.0, and the level of statistical significance was set at $\alpha<.05$. At the time of survey administration, 1107 nursing unit management and staff were working on nursing units in the participating facilities, and a purposeful sample of 342 (31\%) accessed and agreed to participate in the online survey for the study. Forty sets of survey responses were subsequently discarded due to missing data, usually due to interruption /"timing out" of the survey, with failure to log back in and finish the survey. Therefore, responses were tabulated from a total of 302 nursing unit staff members (predominantly registered nurses [RNs]) participating in the study $(302 / 1107 ; 27 \%$ response rate).

\subsection{Sample characteristics}

The following tables report the mean values of nurse sample characteristics for the study. Table 1 displays the mean reported values for staff mix by position and educational level for the nursing units in the hospitals $(\mathrm{n}=10)$ and LTC facilities $(n=30)$ participating in the study. 
Table 1. Mean Percentages of Nursing Unit Staff Mix by Educational Level and Role In Predominantly Rural Healthcare Facilities

\begin{tabular}{|c|c|c|}
\hline & Hospitals $(n=10)$ & Long-Term Care $(n=30)$ \\
\hline \multicolumn{3}{|l|}{ Staff Mix by Educational Level (\%) } \\
\hline LPN (Licensed Practical Nurse) nurse & 14.0 & 27.2 \\
\hline ADN (Associate degree/Diploma) nurse & 63.0 & 8.4 \\
\hline BSN (Bachelor of Science) nurse & 6.0 & 1.9 \\
\hline MSN (Master's of Science) nurse & 1.0 & 0.0 \\
\hline PHD/DNP (Doctoral degree) nurse administrator & $<1.0$ & 0.0 \\
\hline Unlicensed/CNA (Nursing Assistant) & 15.0 & 62.5 \\
\hline \multicolumn{3}{|l|}{ Staff Mix by Role (\%) } \\
\hline Staff Nurse & 54.2 & 31.8 \\
\hline Nursing Assistant & 15.0 & 62.5 \\
\hline Charge Nurse & 20.0 & 3.4 \\
\hline Nurse Manager & 8.8 & 1.3 \\
\hline Director/CNO & $<1.0$ & $<1.0$ \\
\hline Other & $\begin{array}{l}<1.0 \\
\text { (Nurse/Staff educator) }\end{array}$ & $\begin{array}{l}<1.0 \\
\text { (MDS Coordinator) }\end{array}$ \\
\hline
\end{tabular}

The most notable difference in staff mix between the hospitals and LTC facilities is reflected in the greater number of LPN's and nursing assistants working in the LTC's (27.2\% and 62.5\%, respectively) compared to the hospital setting ( $14 \%$ and $15 \%$, respectively). It is also important to note the large number of ADN-prepared nurses (63\%) working in the participating hospitals compared to the LTC setting (8.4\%). Overall, the number of nurses with a Bachelor's degree or higher in educational level is relatively low in comparison to the numbers of ADN and LPN nurses working in the facilities, with $<8 \%$ of nurse professionals possessing a BSN or higher degree in the hospitals, and $<2 \%$ with a BSN or higher degree in the LTC setting.

The mean age range for study participants was $40-49$ years, and $66 \%$ of respondents were 40 years or older, reflective of the aging of the U.S. nursing workforce. The sample was predominantly female (93\%). As might be expected with the reported mean age range of 40-49 years, the majority of survey participants (57\%) also reported 16 or more years of experience in healthcare. In contrast to the common assumption that many nurses leave their positions and are inactive for a period of years and then return to practice later in life, only $12 \%$ of participants reported having a period of inactivity in their health career. For these participants, the most common period of inactivity ranged from 1-5 years (64\%).

Concerning work patterns and roles, more survey respondents worked full-time ( $65 \% ; n=196)$ when compared to part-time $(28 \% ; n=85)$ or per diem $(8 \% ; n=24)$, and also worked a variety of shifts, including days $(65 \% ; n=196)$, evenings $(6 \%$; $\mathrm{n}=18)$, or nights $(17 \% ; \mathrm{n}=51)$. The majority of participants reported working primarily in the patient care role $(69 \%$; $\mathrm{n}=208)$, or a mix of patient care and supervision $(24 \% ; n=73)$, in addition to nurses who functioned as charge nurses or nurse managers $(12 \% ; n=36)$. 


\subsection{Quantitative survey results}

Cross-sectional nursing unit staff survey data were exported from the online survey database and analyzed using Statistical Package for the Social Sciences, version 16.0. Results are presented in tabular format by domain and by each item according to the level of nursing staffs' perceived priority of the topic as a continuing education need on a scale of 1 (very low priority) to 5 (very high priority). Continuing education needs receiving a high or very high priority ranking (mean item score of $\geq 3.5$ ) by $50 \%$ or more of respondents are denoted by an asterisk and considered to be high priority learning needs by nursing unit staff. Student's $t$ was also used to test for significant differences in perceived continuing education needs between the independent groups of nursing unit staff working in the long-term care setting and acute care setting. The actual level of significance is shown for each statistically significant result between acute care and long-term care nursing unit staff.

\section{Nursing process and clinical problems}

Table 2 depicts results for 2 domains reflecting task-oriented clinical practice areas, Nursing Process and Clinical Problems. In these domains, nurses in both acute care and LTC settings reported a need to enhance their knowledge of more commonly treated medical conditions, as well as review aspects of medication administration and drug interactions. For nursing unit staff in LTC settings, optimal handling of patients' behavioral issues and aggression was reported as a priority CE need.

Table 2. Item and Percent Response Indicating Nursing Staffs' Perceptions of Continuing Education (CE) Needs

\begin{tabular}{llll}
\hline $\begin{array}{l}\text { Nursing Process } \\
\text { Item/Topic }\end{array}$ & $\%$ & $\begin{array}{l}\text { Clinical Problems } \\
\text { Item/Topic }\end{array}$ & $\%$ \\
\hline Drug therapy/drug interactions* & $76 \%$ & Cardiovascular problems* & $68 \%$ \\
Assess physical status* & $69 \%$ & Diabetes mellitus* & $65 \%$ \\
Medication administration* & $68 \%$ & Infectious diseases* & $64 \%$ \\
Assess mental status* & $58 \%$ & Pulmonary problems* & $63 \%$ \\
Assess environmental safety* & $57 \%$ & Manage multiple chronic illnesses* & $61 \%$ \\
Health history* & $56 \%$ & Fluid balance* & $58 \%$ \\
Activities of daily living & $44 \%$ & Manage aggressive behavior* & $52 \%$ \\
Assess psychosocial status & $43 \%$ & (verbal/physical) & $48 \%$ \\
Assess spirituality & $25 \%$ & Terminal Illness & $45 \%$ \\
Assess sexuality & $14 \%$ & Confusion & $42 \%$ \\
-- & -- & Immobility & $38 \%$ \\
-- & -- & Mental/Emotional problems & $37 \%$ \\
-- & -- & Sensory deficits & $36 \%$ \\
-- & -- & Speech/Communication & $35 \%$ \\
-- & -- & Bowel/bladder incontinence & $25 \%$ \\
\hline
\end{tabular}

Note. An asterisk $(*)$ indicates that $>$ or $=50 \%$ of nursing staff perceived this area as a high or very high priority CE need.

Table 3. Item and Percent Response Indicating Nursing Staffs' Perceptions of Continuing Education (CE) Needs ${ }^{*}$

\begin{tabular}{llll}
\hline $\begin{array}{l}\text { Nursing Interactions } \\
\text { Question/Topic }\end{array}$ & $\%$ & $\begin{array}{l}\text { Gerontological Care } \\
\text { Question/Topic }\end{array}$ & \% \\
\hline Communication skills* & $58 \%$ & Advanced directives & $42 \%$ \\
Behavioral management techniques & $42 \%$ & Death and dying & $42 \%$ \\
Deal with values, attitudes & $36 \%$ & Major changes associated with age & $39 \%$ \\
Rehabilitation measures & $35 \%$ & Theories of aging & $35 \%$ \\
Reality orientation techniques & $35 \%$ & -- & -- \\
\hline
\end{tabular}

Note. An asterisk $(*)$ indicates that $>$ or $=50 \%$ of nursing staff perceived this area as a high or very high priority CE need. 
Table 3 lists the results for the "Nursing Interactions" and "Gerontological Care" domain items measured by the continuing education survey. For these 2 domains, only one need area, "communication skills", was perceived to be a high priority by nursing unit staff. Table 4 highlights the perceived continuing education needs of nursing unit staff for the Professional Issues domain. For these items, there are several areas perceived as high priority CE needs by nursing unit staff. Continuing education need areas included enhanced teamwork and inter-relating on the nursing units, as well as a desire to engage in lifelong learning and implement evidence-based care as an advocate for patients.

Table 4. Item and Percent Response Indicating Nursing Staffs' Perceptions of Continuing Education (CE) Needs

\begin{tabular}{llll}
\hline $\begin{array}{l}\text { Professional Issues } \\
\text { Question/Topic }\end{array}$ & $\%$ & $\begin{array}{l}\text { Professional Issues } \\
\text { Question/Topic }\end{array}$ & $\%$ \\
\hline Enhance teamwork/relationships on unit* & $67 \%$ & Utilize online (internet) learning* & $50 \%$ \\
Engage in lifelong learning* & $67 \%$ & Improve error-reporting processes & $48 \%$ \\
Implement evidence-based care* & $59 \%$ & Utilize simulation to address learning & $47 \%$ \\
Advocate for patients and families* & $58 \%$ & Learn more about EMR/HIT & $42 \%$ \\
Implement standards of practice* & $58 \%$ & -- & -- \\
\hline
\end{tabular}

Note. An asterisk $(*)$ indicates that $>$ or $=50 \%$ of nursing staff perceived this area as a high or very high priority CE need.

Table 5 presents staff survey results for "Patient Care Issues, Interests, and Problems". Results for this domain reflected several high priority CE needs for nursing unit staff in all facilities, including maintaining patient safety, building a safety culture, and sustaining delivery of high quality care. In addition, staff in both settings acknowledged the need to learn more about the business side of healthcare, in the area of regulatory requirements and reimbursement issues. For this domain in particular, nurse providers in the LTC setting reported significantly higher perceived learning needs to be able to "maintain standards of care", and to enhance "family participation in care", items which support putting patients and families first and "bringing nurses back to the bedside".

Table 5. Item and Percent Response Indicating Nursing Staffs' Perceptions of Continuing Education (CE) Needs

\begin{tabular}{llll}
\hline $\begin{array}{l}\text { Patient Care Issues Interests, Problems } \\
\text { Question/Topic }\end{array}$ & $\%$ & $\begin{array}{l}\text { Patient Care Issues Interests, Problems } \\
\text { Question/Topic }\end{array}$ & \% \\
\hline Standards of care in facility* & $66 \%$ & Regulatory requirements/reimbursement* & $51 \%$ \\
Maintaining safety culture/patient safety $*$ & $63 \%$ & Effects of chronic illness & $44 \%$ \\
Patient rights* & $61 \%$ & Prolongation of life & $35 \%$ \\
Family participation in healthcare* & $53 \%$ & -- & -- \\
\hline
\end{tabular}

\section{Significant differences between long-term care and acute care}

Student's $t$ tests were conducted to determine whether there were any statistically significant differences in perceptions of high priority learning needs between the independent groups of nursing unit staff working in the acute care and long-term care settings. Long-term care nursing unit staff reported significantly higher priority learning needs in the areas of "manage aggressive behavior (verbal/physical)" $(t=2.044, \mathrm{~d} f=300, \alpha=.003)$, "family participation in care" $(t=2.470$, $\mathrm{d} f=300, \alpha=.036)$, and "maintain standards of care" $(t=2.880, \mathrm{~d} f=300, \alpha=.042)$, whereas acute care nursing staff reported a significantly higher priority learning need in the area of "manage a crisis" ( $t=2.122, \mathrm{~d} f=300, \alpha=.050)$.

\section{Discussion}

There were notable similarities, and also some distinct differences, among nursing unit staff perceptions of CE needs among participants who worked in the acute care setting compared to those working in long-term care. To guide the discussion, major results regarding perceived CE needs are highlighted and discussed in relation to current evidence globally on perceptions of rural nurses' CE needs. 


\subsection{Clinical assessment skills (Mental and physical)}

Similar to data reported for rural nursing unit staff in Canada and Australia ${ }^{[6,8]}$, priority continuing education needs for rural nursing unit staff were perceived to be clinical assessment skills (mental and physical), chronic disease management and factors related to patient safety in emergent cases, including managing in a crisis, maternal/perinatal care ${ }^{[6]}$, and knowledge of advanced life support ${ }^{[8]}$. In light of the fact that most participants in these studies self-reported basic "registered nurse" educational preparation, provision of CE content and programming to consistently reinforce basic and advanced clinical assessment and medication administration skills should be beneficial to entry level rural nursing staff.

Rural nurses need to maintain well-rounded generalist preparation to meet most rural hospital patients' acute care needs, whereas complex cases where specialist care is needed are generally triaged and transferred to more distant, high level tertiary facilities ${ }^{[2,6,7]}$. However, if a rural hospital maintains specialty units such as obstetric labour and delivery, emergency department and/or intensive care units, advanced clinical skills must be periodically reviewed and specialty certifications renewed as well ${ }^{[6,8]}$.

In addition to rural hospital nursing unit staff, rural LTC staff members were also surveyed for the current study. For this group, the item "Manage aggressive behavior (verbal and/or physical)" was a statistically significant higher priority learning need than for rural hospital staff $(\alpha=.003)$. In a review of recent literature regarding the appropriate management of aggressive behaviors, Dewing ${ }^{[1]}$ identified patient behaviors that could be categorized as symptoms of agitation, as well as other behaviors that are indicative of aggression (punching, biting, kicking, screaming). Initially, a thorough assessment needs to be conducted to determine precursors to agitated behavior in real time, which may not be achievable in a minimally staffed LTC.

In addition, there are a variety of de-escalation interventions that may be useful in the management of aggressive behaviors, including referencing the patient's imagined world, rather than continually trying to re-orient them to the "real" world ${ }^{[12]}$. However, from an educational perspective, are we still stressing to nursing students and staff that we simply must re-orient the patient or resident in real time at all costs? The heavy patient load that is common for nursing assistants working in LTCs in the U.S. is also likely to contribute to delays in the provision of basic resident care needs that, if belatedly met, can escalate aggressive behaviors. When patient loads are high and time is limited, creative and practical technologically accessible CE content delivery offering simulated role play, live televised role play and other computer-based opportunities in focused modular formats would support rural nursing unit staff in adding to their knowledge and repertoire of mental health (and relevant physical health) assessment skills. Moreover, it appears that mental health assessment in general presents an ongoing challenge for rural nurses across the globe, based on current evidence. Perhaps mental health teaching points need to be re-visited to help nurse educators support nursing students and nursing unit staff in this realm of health care delivery.

\subsection{Communication skills}

Improvement of communication skills was perceived to be a high priority by nursing unit staff in both rural hospital and LTC settings for the current study, and communication skills underlie several variables of import reported for the Canadian ${ }^{[6]}$ and Australian ${ }^{[8]}$ studies, including care of the elderly ${ }^{[6]}$, living and working in rural communities ${ }^{[6]}$, as well as routine patient care ${ }^{[8]}$ and management- and leadership-related duties of rural nurses ${ }^{[8]}$. Indeed, it is reasonable to assert that excellence in communication supports the emotional, intellectual, and physical labour that nurses engage in every day.

In addition, experts tell us that promoting excellence in communication skills has been demonstrated to be paramount to working well in teams and to sustaining patient-centered care ${ }^{[13-16]}$. Excellence in healthcare provider communication improves teamwork, reduces errors and fosters optimal patient health outcomes ${ }^{[13-18]}$. A practical framework for patient communication skills training supports the development of $\mathrm{CE}$ activities to improve the effects of nurse-patient communication on health outcome ${ }^{[19]}$. In a recent study, Cegala ${ }^{[19]}$ reported that if both patients and nurses participated consistently in care interactions, including appropriate post-discharge follow-up, improved patient care outcomes were observed regarding patient perceptions of satisfaction with care, patient participation in care and effective healthcare 
team-patient communications. Continued research efforts in healthcare team and patient communications in relation to the development of healthcare provider CE demonstrates "considerable promise for developing needed theory, promoting interdisciplinary research, and improving the lives of patients" ${ }^{[19]}$.

Another recent CE study of patient care delivery in LTCs utilized an adaptation of De Shazer and colleagues' Solution-Focused Brief Therapy Technique (SFBT) to "shift the nurse-patient conversation from being negative and problem-oriented to being positive and solution-focused" ${ }^{[20,21]}$. According to McGilton and colleagues ${ }^{[21]}$, educating nursing unit staff in the purposeful implementation of the SFBT model allowed patients to share their story for a preset time-frame, without interruption and/or direct patient care interventions. This therapeutic communication model was also reported to support nursing unit staff in driving quality improvements through enhanced nurse and patient perceptions in regard to the effectiveness of teamwork and nurse-patient communications ${ }^{[21]}$. Each of these communication models is useful to consider when planning $\mathrm{CE}$ content and activities to promote enhanced patient-centered care, as well as teambased management of care delivery, in the rural setting.

\subsection{Family participation in care}

For the current study, rural nursing unit providers in LTC settings reported statistically significantly higher perceived learning needs in order to "maintain standards of care" $(\alpha=.042)$, and to enhance "family participation in care" $(\alpha=.036)$. These items support putting patients and families first and foster "bringing nurses back to the bedside", notions that are at the core of several patient-centered care initiatives currently ongoing in many U.S. hospitals ${ }^{[13,14,22]}$. The global rural nursing studies reviewed here ${ }^{[6,8]}$ also reflect rural nurses' perceptions that family participation is important to patient-centered care delivery, in that the aforementioned $\mathrm{CE}$ need variables related to working and living in a rural setting ${ }^{[6]}$ affords the nurse the opportunity to become familiar with families and neighbors in a close-knit community. When nursing unit staff members know the person and family they are caring for, this can reinforce the desire to deliver care in a patient-centered manner, and accountability for quality of care is naturally and proximally present post-discharge.

\section{Linking continuing education to quality improvement}

The priority CE needs as perceived by nursing unit staff in this and global rural-based CE studies reflect the importance of the patient-centered care movement that is currently exemplified in the U.S. through quality improvement (QI) initiatives promoted by the Institute of Medicine ${ }^{[13,14]}$, and the QI framework "Transforming Care at the Bedside" [22]. The skill list emerging from these initiatives serve to remind us as educators of a teaching concept that these initiatives exhort healthcare providers (and especially nursing unit staff) to apply in practice. This key concept describes working with "collective mindfulness" as a healthcare team at the patient's bedside and throughout a healthcare system ${ }^{[16]}$. The concept of collective mindfulness is sometimes overlooked as an underpinning to QI strategies and healthcare provider learning, but it is defined as heedful (purposeful, attentive) interrelating to connect sufficient individual know-how to meet ever-changing situational demands at work ${ }^{[15,16]}$. According to Weick ${ }^{[16]}$, collectively mindful teams make fewer errors, and are the hallmark of a high reliability organization (HRO). Study team members are seeking ways to incorporate this concept effectively into creative $\mathrm{CE}$ activities from the rural health care delivery perspective. Additional research is needed to determine potential benefits of applying the collective mindfulness ${ }^{[16]}$ concept to rural nurses' CE programs.

\section{Embracing and promoting the need for rural nurses' continuing education}

Ongoing continuing education, a desire for lifelong learning, and an emphasis on the progressive developmental growth of nurses have been clearly recognized needs for decades in the nursing profession ${ }^{[23-25]}$. However, in this study, nursing unit staff in the LTC and acute care facilities reported a lack of clearly defined incentives to participate in CE; for example, the state in which this study was conducted has no formal annual requirement for nurses' CE. Resources to support substantive $\mathrm{CE}$ activities were lacking in adequate human, financial and technical supports to help drive CE delivery in a consistent 
manner. All types of healthcare facilities need to promote and support clinical knowledge development. According to Benner's "Novice to Expert" theory ${ }^{[23]}$, the ongoing development of a proficient or expert nurse from a novice nurse requires multiple learning opportunities and methods, including clinical experiences, case studies, nursing rounds and continuing education opportunities ${ }^{[23,24]}$. These kinds of teaching opportunities present multiple complex challenges in the rural setting, as few rural health care facilities have adequate financial and/or technological resources to provide them.

The results of this study also revealed that the majority of nursing unit staff in the participating rural acute care hospitals included associate degree prepared registered nurses (RNs). Moreover, most of the nursing care provided in the rural LTC facilities was provided by non-licensed certified nursing assistants (CNAs). This raises some concerns, as basic health care workforce entry training and skills are emphasized in a CNA certificate, licensed practical nurse or an associate degree program. In contrast, baccalaureate-prepared nurses are educated to enter professional practice with skills that move beyond the basic "habitual skill knowledge" ${ }^{[18]}$ of routine daily care to include a distinct focus on "intelligent skill knowledge" ${ }^{[18,26]}$. Intelligent skill knowledge "... involves the nurse perceiving and actively thinking about care rendered to a person, demonstrating the ability of discernment toward intelligent action" ${ }^{[18]}$. In contrast, habitual skill knowledge simply enables a person to unreflectively perform necessary patient care routines ${ }^{[18,26]}$.

Intelligent skill knowledge is purposefully developed in baccalaureate and graduate level nursing programs, and involves leading students to engage in systems thinking via analysis, synthesis and evaluation of health care delivery methods, models and processes. Through the application of systems thinking, a nurse professional is supported in their quest to go beyond habitual skill knowledge to learn how to promote and sustain evidence-based practice and continuous quality improvements in delivery of care at individual, community, regional and global levels. It is possible then, to surmise that the associate degree prepared RN, particularly one working in a rural LTC facility, may never progress beyond a novice nurse without incentives and support for periodic CE activities. Preventing this potential knowledge stagnation will require alternative budget streams, creative partnerships with universities, and innovative teaching- learning methods. CE delivery methodologies will also require creative approaches that are technology-based to deliver vital educational opportunities to all rural healthcare providers.

\section{Conclusions and recommendations}

Study results revealed distinct learning needs for rural nursing unit staff, pointing to the need for relevant, evidence-based content in relation to $\mathrm{CE}$ development and delivery in rural settings. The potential for nursing knowledge stagnation among entry level nursing unit staff in rural settings needs to be addressed to help break down the isolation barriers impacting the knowledge, attitudes and behaviors of care providers practicing in rural facilities. The study team proposes the following advocacy efforts with multiple relevant stakeholders to support $\mathrm{CE}$ activities in rural communities:

- State policy reforms to include CE requirements for nursing unit staff

- Academic-practice partnerships to proactively support CE learning needs

- Innovative technological delivery methods to bridge the isolation gap in rural settings

- Collaborative grant and contract opportunities

It is hoped that these efforts will provide a launching point for future initiatives designed to address the CE gaps in rural health care settings. The provision of relevant, evidence-based CE is an integral part of maintaining a highly competent rural nursing workforce.

\section{References}

[1] Olade RA. Evidence-based practice and research utilization activities among rural nurses. Journal of Nursing Scholarship. 2004; 36(3): 220-225. PMid:15495490 http://dx.doi.org/10.1111/j.1547-5069.2004.04041.x 
[2] Jukkala AM, Henly SJ, Lindeke LL. Rural perceptions of continuing professional education. The Journal of Continuing Education in Nursing. 2008; 39(12): 555-563. http://dx.doi.org/10.3928/00220124-20081201-08

[3] McCoy C. Professional development in rural nursing: Challenges and opportunities. The Journal of Continuing Education in Nursing. 2009; 40(3): 128-131. http://dx.doi.org/10.3928/00220124-20090301-08

[4] Penz K, D’Arcy C, Stewart N, Kosteniuk J, Morgan D, Smith B. Barriers to participation in continuing education among rural and remote nurses. The Journal of Continuing Education in Nursing. 2007; 38(2): 58-66. PMid:17402377

[5] Hughes E. Nurses' perceptions of continuing professional development. Nursing Standard. 2005; 19(43): 41-49.

[6] Macleod MLP, Lindsey E, Ulrich CH, Fulton T, John N. The development of a practice-driven, reality-based program for rural acute care registered nurses. The Journal of Continuing Education in Nursing. 2008; 39(7): 298-304. http://dx.doi.org/10.3928/00220124-20080701-03

[7] Munroe D, Duffy P, Fisher C. Fostering evidence-based practice in a rural community hospital. Journal of Nursing Administration. 2006; 36 (11): 510-512. PMid:17099434 http://dx.doi.org/10.1097/00005110-200611000-00004

[8] Kenny A, Duckett S. Educating for rural nursing practice. Journal of Advanced Nursing. 2003; 44(6): 613-622. http://dx.doi.org/10.1046/j.0309-2402.2003.02851.x

[9] Fairchild RM, Everly M, Bozarth L, Bauer R, Walters L, Sample M, Anderson L. A qualitative study of continuing education needs of rural nursing unit staff: The nurse administrator's perspective. Nurse Education Today. 2012; in press. http://dx.doi.org/10.1016/j.nedt.2012.05.023.

[10] Claflin N. Continuing education needs assessment of acute care and long-term care nurses. The Journal of Continuing Education in Nursing. 2005; 36(6): 263-270. PMid:16372715

[11] Dewing J. Responding to agitation in people with dementia. Nursing Older People. 2010; 22 (6): 18-25. PMid:20632545

[12] Somes J, Donatelli NS, Kuhn S. Controlling aggressive behavior in the geriatric patient. Journal of Emergency Nursing. 2011 ; 37 (3): 275-277. PMid:21440292 http://dx.doi.org/10.1016/j.jen.2011.01.008

[13] Institute of Medicine. Crossing the Quality Chasm: A New Health System for the 21st Century. 2001; Washington, DC: National Academy Press.

[14] Institute of Medicine. Keeping Patients Safe: Transforming the Work Environment of Nurses. 2004; Washington, DC: National Academy Press.

[15] Weick, KE. Making sense of the organization. Oxford UK: Blackwell Publishers, 2001. PMid:11494412

[16] Weick KE. The reduction of medical errors through mindful interdependence. In M.M. Rosenthal \& K.M. Sutlcliffe (Eds.), Medical Error: What Do We Know? What Do We Do? San Francisco, CA: John Wiley and Sons, Inc. 2002; 84-100.

[17] American Association of Critical-Care Nurses [Internet]. The AACN synergy model for patient care. 2011. Available from: www.aacn.org/wd/certifictions/content/synmodel.pcms\#Basic

[18] Moody RC, Pesut DJ. The motivation to care: Application and extension of motivation theory to professional nursing work. Journal of Health, Organization and Management. 2006; 20(1): 15-48. http://dx.doi.org/10.1108/14777260610656543

[19] Cegala DJ. Emerging trends and future directions in patient communication skills training. Health Communications. 2006; 20 (2): 123-129. PMid:16965249 http://dx.doi.org/10.1207/s15327027hc2002_3

[20] De Shazer S, Berg IK, Lipchik E, Nunnally E, Molnar A, Gingerich W, et al. Brief therapy: Focused solution development. Family Process. 1986; 25 (2): 207-21. PMid:3732502 http://dx.doi.org/10.1111/j.1545-5300.1986.00207.x

[21] McGilton K, Irwin-Robinson H, Boscart V, Spanjevic L. Communication enhancement: Nurse and patient satisfaction outcomes in a complex continuing care facility. Journal of Advanced Nursing. 2006; 54 (1): 35-44. PMid:16553689 http://dx.doi.org/10.1111/j.1365-2648.2006.03787.x

[22] Needleman J, Parkerton PH, Pearson ML, Soban LM, Upenieks VV, Yee T. Impacts on the Learning Community Hospitals of Transforming Care at the Bedside. American Journal of Nursing. 2009; 109: 59-65. PMid:19826344 http://dx.doi.org/10.1097/01.NAJ.0000362028.00870.e5

[23] Benner P. From novice to expert: Excellence and power in clinical nursing practice. Menlo Park: Addison-Wesley, 1984.

[24] Benner, P., Sutphen, M, Leonard, V, Day, L. Educating Nurses: A call for radical transformation. Carnegie Foundation \& Jossey-Bass, 2009.

[25] Billings DM, Halstead JA. Teaching in Nursing: A Guide for Faculty. St. Louis, MO: Saunders Elsevier, 2009.

[26] Glen S. Emotional and motivational tendencies: the key to quality nursing care? Nursing Ethics. 1998; 5 (1): 36-42. PMid:9505713 